\title{
Registro poblacional de incidencia y mortalidad por cáncer en Concordia, Entre Ríos
}

Resumido de: Loria D, Prince M, Herrera L. Cáncer en el Departamento de Concordia, Entre Ríos. Datos de incidencia y mortalidad, 1990 a 1997. Gobierno de la Provincia de Entre Ríos. Secretaría de Estado de Salud.

\section{Objetivos}

Conocer la distribución (sexo, edad y localización) incidencia y mortalidad de los tumores malignos en el departamento de Concordia, Entre Ríos (Argentina) así como sus variaciones temporales y seculares; contribuir a la planificación y evaluación de medidas preventivas (especialmente respecto del cáncer de mama y cérvix) y estimular la creación de otros registros epidemiológicos en la provincia de Entre Ríos y el resto del país.

\section{Diseño}

Registro sistemático y continuo con base poblacional de todos los casos nuevos de cáncer (casos incidentes).

\section{Población cubierta y área geográfica}

Individuos con más de seis meses de residencia en el Departamento de Concordia. La población promedio en el período 1990-1997 fue 144256 habitantes.

\section{Fuente de los datos}

Los registradores revisan desde 1990 todas las fuentes que pueden proveer información sobre nuevos diagnósticos tumorales, basándose en todas las instancias que suelen recorrer las personas a quienes se les ha diagnosticado un tumor: 1) proceso diagnóstico ,2) tratamientos oncológicos y 3) informes estadísticos de defunción .

\section{Procedimiento de la recolección}

Visita periódica a Hospitales Públicos, Clínicas y Sanatorios Privados; revisión de informes de laboratorios de anatomía patológica y citodiagnóstico de Concordia, Chajarí, Concepción del Uruguay y Villaguay; así como de servicios de imágenes y radioterapia, archivos de las obras sociales y de la asociación médica de Concordia. Cuando se registra un caso nuevo a través del informe de defunción, se realiza una búsqueda retrospectiva de la información en las fuentes mencionadas.

\section{Diagnóstico}

Se considera momento de diagnóstico a la fecha del informe anatomopatológico y, en los casos sin confirmación microscópica, cuando el médico menciona por primera vez el tumor. Los pacientes que desarrollen más de un tumor primario son ingresados al registro una vez por cada uno de ellos.

\section{Resultados}

A través del denominador poblacional obtenido de la fuente censal, se calculan las tasas de incidencia (crudas y estandarizadas) de los distintos tipos de tumores. Además, cada caso nuevo que es ingresado en el registro ingresa a una cohorte, lo que permite estimar con base poblacional la tasa de recurrencia (ej. aparición de metástasis) y de sobrevida.

\section{Resultados principales}

Incidencia

El número de nuevos casos en el período1990-1997 fue 1377 en hombres y 1451 en mujeres, lo que corresponde a una incidencia estandarizada de $284,5 / 100000$ y $238,4 / 100000$ respectivamente.

Si se la compara con la de la primera mitad del período (19901993) analizado, la incidencia de tumores en ambos sexos para todos los sitios fue algo mayor en la segunda mitad (1994-1997).

En los varones, los tumores de pulmón ocuparon el primer puesto en el ranking en el grupo de 40 a 60 años (22,4\%); y el segundo en los grupos de 15 a 39 años (10,3\%).

El cáncer de cérvix fue el más frecuente en las mujeres de 15 a 39 años $(30,1 \%)$

Ver figuras 1 y 2

Se registraron 23 casos de tumores en menores de 15 años.
Figura 1: porcentaje según grupo etáreo y sexo para las principales localizaciones en hombres.

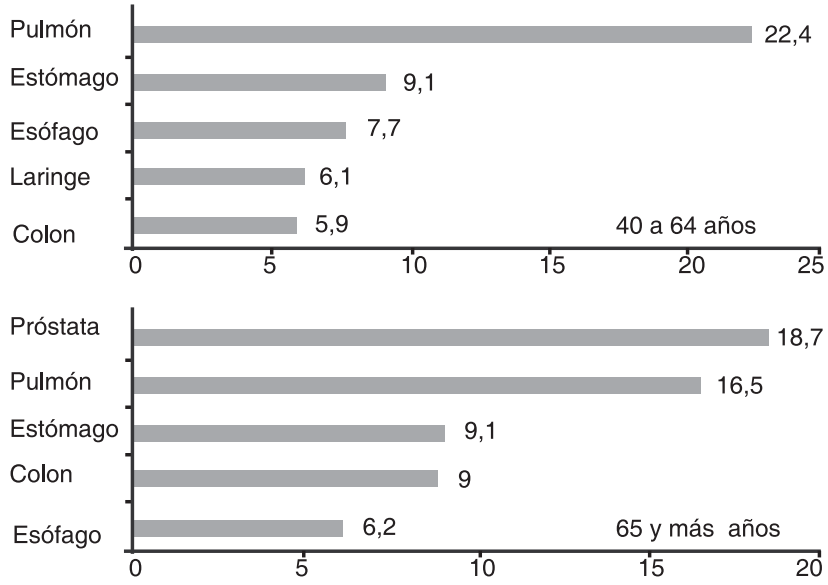

Figura 2: porcentaje según grupo etáreo y sexo para las principales localizaciones en Mujeres.

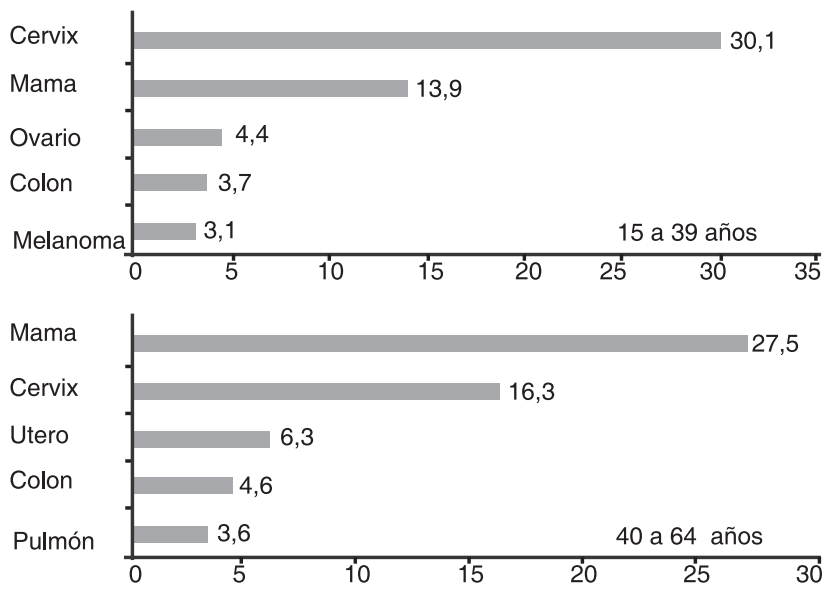

Mortalidad

Los tumores de pulmón fueron los responsables del $23,8 \%$ de las defunciones por cáncer en hombres, seguidos por los de estómago $(10,4 \%)$ próstata $(7,9 \%)$ esófago $(7,8 \%)$ y colon $(5 \%)$. Ver figura 3

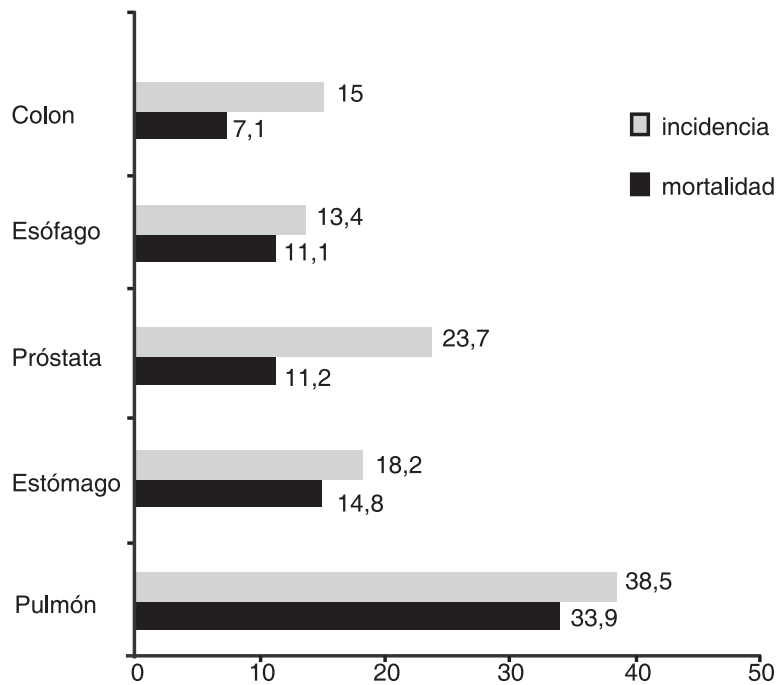

Figura 3: mortalidad en incidencia por cáncer en varones desde 1990 a 1997 cada 100000 habitantes en Concordia, Entre Ríos. 
Las causas más importantes de muerte por cáncer en mujeres fueron: mama $(18,6 \%)$ cérvix $(7,8 \%)$ estómago $(6,5 \%)$ páncreas $(6,4 \%)$ y colon $(5,7 \%)$.Ver figura 4

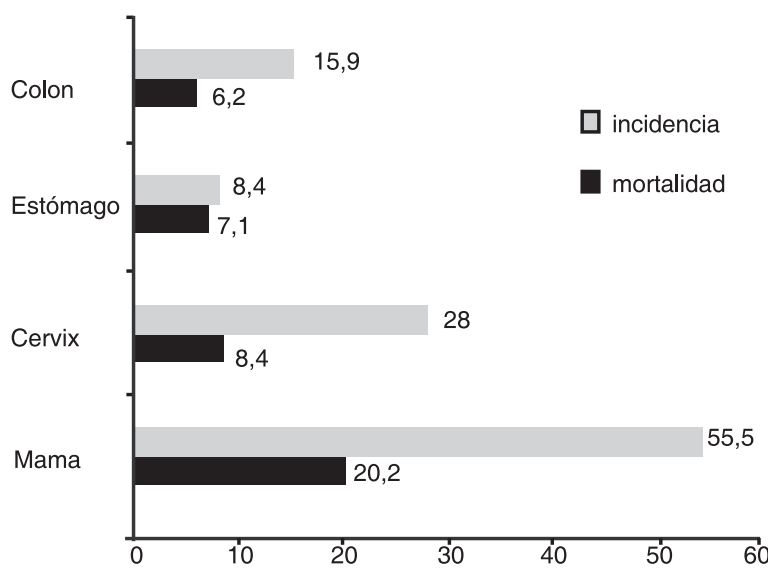

Figura 4: mortalidad en incidencia en por cáncer en mujeres desde 1990 a 1997 cada 100000 habitantes en Concordia, Entre Ríos.

En algunas localizaciones tumorales se pudo calcular la sobrevida a cinco años. Ver cuadro 1.

Cuadro 1: sobrevida global a cinco años según la localización del tumor.

\begin{tabular}{l|c} 
Localización & Sobrevida global a cinco años \\
\hline Mama & $71 \%$ \\
\hline Invasor de cévix & $55 \%$ \\
\hline Próstata & $66 \%$ \\
\hline Colorrectal & $56 \%$ \\
\hline
\end{tabular}

\section{Discusión}

En 1998, se implementó en Concordia un programa para la detección precoz de cáncer de cérvix, que no existía durante el período que se presenta en este resumen (1990 y 1997). Si bien este programa fue reformulado en 2000 , aún no encontramos un aumento de la incidencia de esta patología, como ha ocurrido en países desarrollados en los que ya se observó el impacto de estas estrategias poblacionales de prevención secundaria.

La baja incidencia de cáncer de pulmón encontrada en mujeres concuerda con la baja prevalencia de tabaquismo en dicha población durante el lapso que presentamos ya que el $63 \%$ nunca habían sido fumadoras. Esta tendencia lamentablemente se está revirtiendo ya que la edad de inicio es cada vez más temprana, por lo que se espera un aumento de la incidencia de cáncer de pulmón es este grupo en el futuro.

El importante aumento observado en la incidencia ajustada de cáncer de próstata (19,3/100000 habitantes/año en 1990-93 a 35,4/100000 habitantes/año en 1994-1997) puede ser atribuido, en parte, a la mayor difusión de las prácticas para su detección pre$\mathrm{coz}$, mientras que el aumento registrado en su mortalidad se deba probablemente a la mejor determinación de la causa de muerte. Parte del aumento de algunas tasas de incidencia en el período 1994-1997 respecto del período 1990-1993 puede ser atribuido a la mejora del registro.

Sin embargo, existiría un importante subregistro de los tumores ocurridos en los menores de 15 años ya que muchos de ellos se atienden en centros de derivación situados fuera del Departamento de Concordia o en otras provincias.
Figura 5: incidencia ajustada en Concordia de algunos tumores en varones comparada con la de otros registros poblacionales de cáncer.

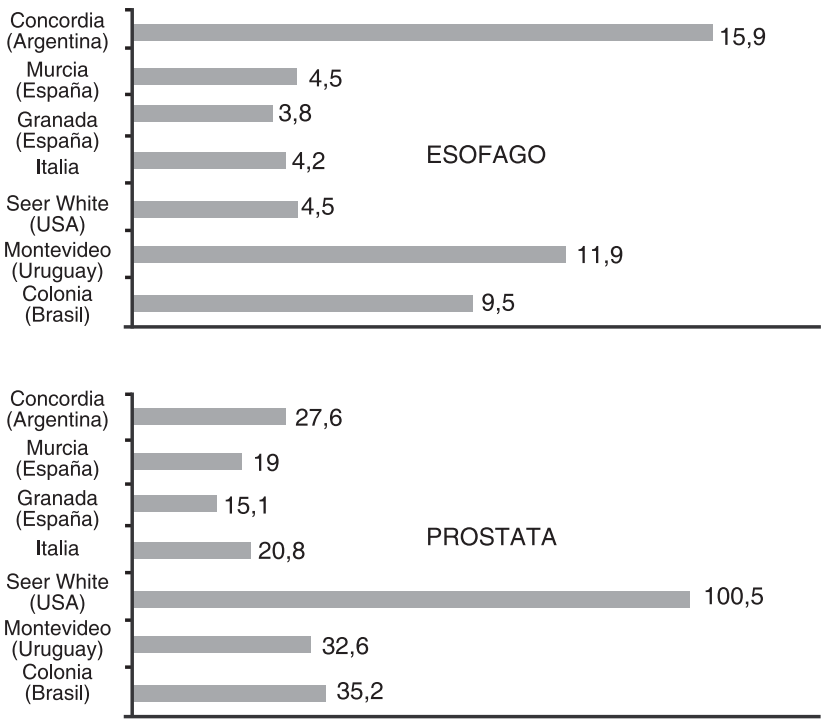

Como muestran las figuras 5 y 6 , la incidencia de algunos tumores en Concordia es diferente a la de otros registros poblacionales, lo que remarca la cautela que se debe tener al extrapolar datos de otras regiones y la importancia de que contemos con estrategias para recoger información epidemiológica local.

Figura 6: incidencia en ajustada Concordia de algunos tumores en mujeres comparada con la de otros registros poblacionales de cáncer.
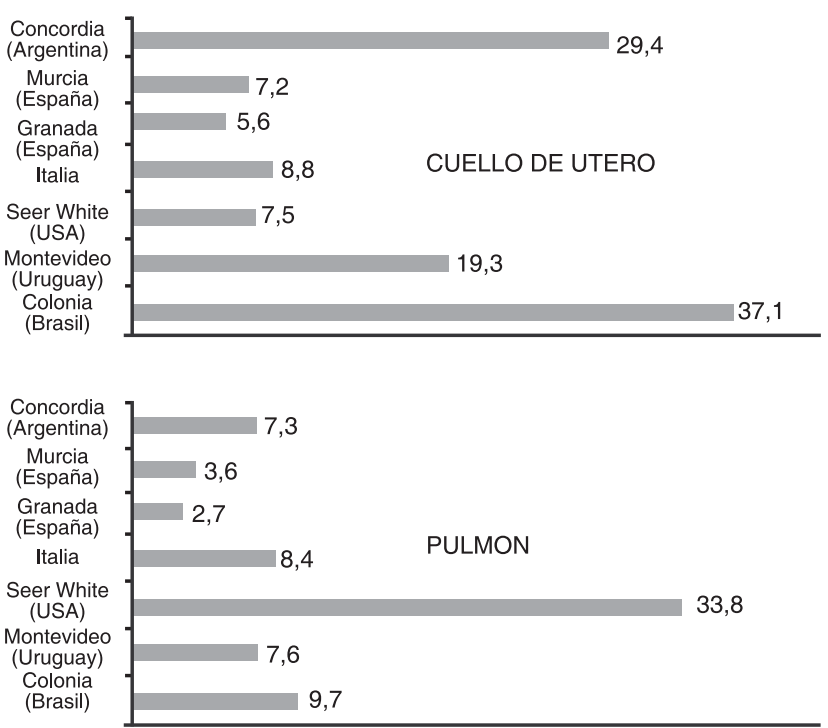

Conclusiones: Luego de más de diez años de registro poblacional de cáncer en Concordia se abordó el proyecto de extenderlo a toda la provincia (aproximadamente 1.152.000 habitantes).Es de esperar que la información obtenida en este tipo de trabajo continuo de vigilancia epidemiológica pueda ser la base para mejorar la planificación sanitaria, estimular la investigación, desarrollar programas de prevención primaria, secundaria y terciaria y contar con la información necesaria para medir su impacto.

Fuente de financiamiento: los coordinadores del proyecto trabajan ad honoren, los registradores perciben salarios de la administración pública provincial, los programas informáticos son gratuitamente provistos por la Agencia Internacional para la Investigación del Cáncer.

Palabras clave: cancer/epidemiología, cancer/diagnóstico, cancer, epidemiología, registros de población. 